\title{
Kinetic responses of running shoes submitted to prolonged use: a case report
}

CDD. 20.ed. 796.023

\begin{tabular}{|c|c|}
\hline $\begin{array}{r}\text { Roberto BIANCO* } \\
\text { Fernanda Michelone ACQUESTA* } \\
\text { Ana Paula da Silva AZEVEDO } \\
\text { Carina Helena Wasem FRAGA* } \\
\text { Sandro BARONE* } \\
\text { Luiz MOCHIZUKI/*** } \\
\text { Alberto Carlos AMADIO* } \\
\text { Júlio Cerca SERRÃO* }\end{array}$ & $\begin{array}{l}\text { "Escola de Educação } \\
\text { Fisica e Esporte, } \\
\text { Universidade de São } \\
\text { Paulo. } \\
\text { "*Escola de Artes, Ciên- } \\
\text { cias e Humanidades, } \\
\text { Universidade de São } \\
\text { Paulo. }\end{array}$ \\
\hline
\end{tabular}

\begin{abstract}
The purpose of this study was to analyze the kinetic responses of running shoes submitted to prolonged use. Four shoes (R1, R2, T1 and T2) were used for $500 \mathrm{~km}$ except for T1 which was used for $1000 \mathrm{~km}$. At every $100 \mathrm{~km}$, Ground Reaction Force (GRF) and plantar pressure measurements were collected. In T2, there was a slight trend of increase in Loading Rate of the first peak of GRF with increasing distance. R1, R2 and T1 showed no trend of increase in Loading Rate values. Shoe T1 showed a slight tendency of increase in Loading Rate values when the distance was considered up to $1000 \mathrm{~km}$. All running shoes showed a high variability in peak pressure values, but no trend of increase was observed. On the contrary, $\mathrm{T} 1, \mathrm{~T} 2$ and $\mathrm{R} 2$ showed a trend of decrease in peak pressure values with increasing use. Therefore, there is no consistent evidence or trend of increase in Loading Rate and Peak Pressure values that would suggest worsening in external load attenuation.
\end{abstract}

KEY WORDS: Biomechanics; Footwear; Cumulative use.

\section{Introduction}

Many runners are concerned about the durability of their running shoes. It is believed that prolonged use can cause gradual deterioration to the shoe that could reduce the running shoe's capability in attenuating the mechanical loads ${ }^{1}$.

This decrease in the attenuation of impact forces was first observed in running shoes subjected to an artificially mechanical compaction. It was also observed that different running shoes showed distinct responses when artificially compressed, suggesting that such responses are dependent on the running shoe characteristic ${ }^{2-3}$.

In latter studies with subjects using the running shoes for $700 \mathrm{~km}$, structural damages could be observed to the midsole of the running shoes. These damages were microscopic cracks found in internal cells of the material as a consequence of cumulative compaction ${ }^{4}$. The authors also observed an increase in plantar peak pressure and this was attributed to the deterioration of the midsole components.

Although mechanical tests indicate that the running shoe suffers a progressive deterioration with use, the results of biomechanical tests do not point in the same direction. While in one study, the mechanical load tended to increase with use ${ }^{4}$, other studies did not indicate that the mechanical load increased with time of use $\mathrm{e}^{3,5-8}$.

In running shoes, the response to usage is dependent on the construction features of the shoe. Though usually EVA foam is employed in midsole, nowadays, it is common to find different technologies associated to EVA. While some running shoes, such as training shoes, are designed to resist more to usage, others, such as racing shoes, were meant to be used only for short periods of time. 
The differences between racing shoes and training shoes are not yet established. One evidence indicates that racing shoes are less capable of attenuating external forces $^{3}$, but other evidences showed no difference between racing and training shoes 5 . Racing shoes are usually lighter in weight, because they are manufactured with less material than training shoes and, therefore, supposedly, they have lower durability, meaning that they should be replaced sooner than training shoes. Until now, there has been little evidence to confirm or refute this belief with respect to racing shoes.

Therefore, the objective of this study was to characterize and analyze the Ground Reaction Force (GRF) and Plantar Pressure responses of running

\section{Method}

\section{Sample}

Two racing shoes (R1 and R2) and two training shoes (T1 and T2) were evaluated. The running shoes were classified as racing or training shoes by manufacturers and presented as the main difference, the mass of footwear. These shoes were evaluated after a long period of use: R1, R2 and T2 shoes were used for $500 \mathrm{~km}$ and T1 was used for 1000 $\mathrm{km}$. For these assessments, one ultramarathonist athlete was chosen to take part in this study. The athlete is a 35-year old long distance runner, with body weight of $66 \mathrm{~kg}$ and height of $1.68 \mathrm{~m}$. The athlete had nine years of running experience, with an average running distance of 150 and $200 \mathrm{~km}$ per week. The athlete is a rearfoot striker and his arch index, as described by CAVANAGH and RODGERS ${ }^{9}$, was classified as a normal foot type. He did not suffer any injuries in the last five years. The choice of one athlete had the intention of investigating how some running shoe types would respond to high use. The use of one subject allowed reducing the variability that different athletes would cause in the results. Since only one subject was used, the variation in the kinetic responses could more easily be attributed to the running shoe differences or to the usage conditions. The athlete gave informed consent to participate in this project and the experimental procedure was approved by the local Research Ethics Committee (protocol no 65, approved on 27/08/2004). shoes imposed to prolonged use. The specific objectives were: a) to investigate possible differences in GRF and in plantar pressure distribution in racing and in training shoes; $\mathrm{b}$ ) to analyze if the attenuation of mechanical loads is affected in racing and training running shoes after $500 \mathrm{~km}$ of use. The hypotheses of this study are: a) the impact attenuation will not be affected by usage in either shoes, but Plantar Peak Pressure will show some increase, as the running shoes become used more and more; $b$ ) the racing shoes will present higher Loading Rates and higher peak pressures than training shoes and these specific racing shoes will also present gradual and faster deterioration as a consequence of usage.

\section{Running shoes}

Four running shoes were analyzed: Two training shoes (T1 and T2) and two racing shoes (R1 and $\mathrm{R} 2)$. All the shoes were constructed using different proportions of ethylene vinyl acetate (EVA) and polyurethane (PU) foams. The T1 shoe had an EVA midsole with a Wave ${ }^{\circledR}$ technology inserted in its midsole, the T2 shoe had a Phylon midsole with an Air-sole unit in its full length, the R1 shoe had an EVA midsole with the adiPRENE ${ }^{+\otimes}$ technology in the heel and full forefoot and the R2 shoe had a dual density EVA midsole (DuoSole ${ }^{\circledR}$ technology) with encapsulated gel in its anterior and posterior region. The racing shoes had lower masses than the training shoes. (210g in R1, 255g in R2, 345g in $\mathrm{T} 1$ and $335 \mathrm{~g}$ in $\mathrm{T} 2)$.

\section{Experimental procedure}

Two instruments were used for data collection: The Gaitway Instrumented Treadmill System 9810S1x (Kistler Instrumented Corp.; Amherst, USA) and The F-scan ${ }^{\circledR}$ System in-shoe analysis (Tekscan Inc.; South Boston, USA). The Gaitway System consists of an instrumented treadmill with two piezoelectric force platforms assembled in series at its base. The F-scan ${ }^{\circledR}$ System consists of insoles containing 960 resistive sensors. The insoles are positioned inside the running shoes to measure the plantar pressure distribution at each stance phase in human locomotion. Each insole 
was trimmed to fit in the subject's shoes, and therefore the number of sensors reduced proportionally to the runners shoe size.

The protocol involved a 20 -minute period of warming up and an adaptation to the experimental condition. The running speed of the first 10 minutes was freely controlled by the runner, but at the last 10 minutes the speed was set at $14 \mathrm{~km} \cdot \mathrm{h}^{-1}$. This running speed was chosen because it represents a moderate intensity for the subject. After the 20 minutes, two acquisitions at the running speed of $14 \mathrm{~km} \cdot \mathrm{h}^{-1}$ were made over a period of 10 seconds, with a sampling frequency of $1 \mathrm{kHz}$, on the Gaitway Instrumented Treadmill System (9810S1x). The 10 seconds allowed an acquisition of approximately 12 stance phases with each foot. These 24 stances were grouped for the analysis of GRF parameters. The plantar pressure was recorded by the F-scan ${ }^{\circledR}$ System insoles, in three consecutive samples of 4.17 sec, with a sampling frequency of $120 \mathrm{~Hz}$ which were made at the running speed of $14 \mathrm{~km} \cdot \mathrm{h}^{-1}$. The three sets allowed for approximately 6 stance phases for each foot which were used together for plantar pressure distribution analysis. Because of high horizontal forces produced while running, one pair of insoles could be used exclusively for one data collection only. Therefore, for each F-scan ${ }^{\circledR}$ System acquisition, a new pair of insoles was used. The two systems were recalibrated at each time a data collection was conducted. The runner's body mass was registered at every data collection to minimize normalization errors due to body mass variations.

The T2, R1 and R2 shoes were analyzed is six different distances of use (new, $100 \mathrm{~km}, 200 \mathrm{~km}, 300$ $\mathrm{km}, 400 \mathrm{~km}$ and $500 \mathrm{~km}$ ), and shoe T1 was analyzed equally at every $100 \mathrm{~km}$ but until a cumulative use of $1000 \mathrm{~km}$. The other shoes were also submitted to higher distances than $500 \mathrm{~km}$, but because of technical difficulties, the higher distances could not be used. Nevertheless, the $1000 \mathrm{~km}$ data from T1 was kept because this distance was not investigated until the present day and the results seemed interesting to analyze. The control was made by the athlete who registered the course and training characteristics on a spreadsheet. The athlete used the running shoes only on asphalt at his training sessions. The use of only one type of ground was important to control the possibly different compaction that different grounds could have generated. The training session varied between 15 and $30 \mathrm{~km}$ and the average running speed was $14 \mathrm{~km} . \mathrm{h}^{-1}$. The runner was free to choose the running shoe he wanted to use in each training session, but he was asked not to use the same shoe repeatedly. As a consequence, on different days, but at a similar interval of time (approximately one month) every shoe was reanalyzed.

\section{Data analyses}

The GRF parameters were analyzed in Matlab 6.5 software (The Mathworks Inc.; Natick, USA) and the plantar pressure variables were treated at the software system F-scan 4.10 (Tekscan Inc; South Boston, USA). The vertical component of GRF corresponding to each stance phase was cut and filtered. The GRF data were filtered with a low pass Butterworth of second order with a cut off frequency of $140 \mathrm{~Hz}$. Loading Rate was calculated by dividing first peak values by the time interval between contact initiation and the occurrence of the first peak.

The peak pressure values were obtained by plotting the highest pressure values registered at each sensor during the stance phase. The total contact area was divided into four different regions: rearfoot, midfoot, forefoot and Hallux. From these regions, the highest magnitude of pressure was collected for each stance phase in every running condition, as described earlier in BIANCO et al. ${ }^{8}$. Thus, the peak pressure values correspond to a pressure value obtained by one sensor at each foot region and it corresponds to the highest value measured at that region for the entire stance phase. Since the peak pressure values correspond to one instant at a time and it is not the same instant for the different foot regions, the pressure value could not be associated to GRF values. Another problem that could not allow the synchronization between the two systems was that they were used separately.

No statistical procedure was applied to investigate the statistical significance of the differences observed between the conditions; instead, a visual analysis of graphed data was used to estimate trends in data series as described by WOLERY and Harris ${ }^{10}$ and WhITE and HARING $^{11}$. This analysis is known as the split-middle method of trend estimation and involves a procedure that investigates the distribution of the values in the different conditions. The data trend was evaluated to identify increases or decreases in discrete parameter values. As stated before, this analysis does not allow statements of statistical significance. 


\section{Results}

In the new condition, the Loading Rate values of R2 $(84.05 \pm 6.58 \mathrm{~N} / \mathrm{ms})$ appeared to be higher than of the other shoes: R1 $(70.21 \pm 6.0 \mathrm{~N} / \mathrm{ms}), \mathrm{T} 1$ $(69.51 \pm 4.7 \mathrm{~N} / \mathrm{ms})$ and T2 $(60.62 \pm 5.7 \mathrm{~N} / \mathrm{ms})$. The lowest Loading Rate value was observed in T2. At $500 \mathrm{~km}$ of usage, R2 still showed higher Loading Rate values $(81.61 \pm 9.1 \mathrm{~N} / \mathrm{ms})$ when compared to R1 $(77.29 \pm 9.5 \mathrm{~N} / \mathrm{ms}), \mathrm{T} 1(72.19 \pm 7.6 \mathrm{~N} / \mathrm{ms})$ and T2 $(70.64 \pm 5.1 \mathrm{~N} / \mathrm{ms})$, but the differences apparently decreased between the shoes.

Some variation was observed between conditions in Loading Rate (FIGURE 1). Except for the T2 shoe, no clear trend of increase could be observed in Loading Rate between conditions. In T2, a trend of increase in Loading Rate was observed until 200 km, followed by a change in trend after this condition.

The T1 shoe was analyzed until $1000 \mathrm{~km}$ of use. Loading Rate values showed a trend of a consistent and gradual increase (FIGURE 2). The difference between the new condition and the $1000 \mathrm{~km}$ condition was $18 \%$. Data from $700 \mathrm{~km}$ was not presented because of technical problems during data collection.

Peak Pressure values are presented in FIGURES 3 and 4. Pressure distribution showed a high variation in values in all running shoes and in all regions of the foot (Rearfoot, midfoot, hallux and Forefoot), through the different distances of use. In each running shoe, a different trend could be observed in pressure distribution.

For instance, T2 and R2 showed a trend of decrease in peak pressure values with increasing use, especially in HPP and FPP (FIGURE 3); $\mathrm{R} 1$ showed no clear trend and a higher variability between conditions (FIGURE 3) and T1 showed a very high variability until $500 \mathrm{~km}$ of use with no clear trend, but the variability decreased after 500 $\mathrm{km}$ and the peak pressure values in all foot regions apparently decreased compared to the first $500 \mathrm{~km}$ of use (FIGURE 4).

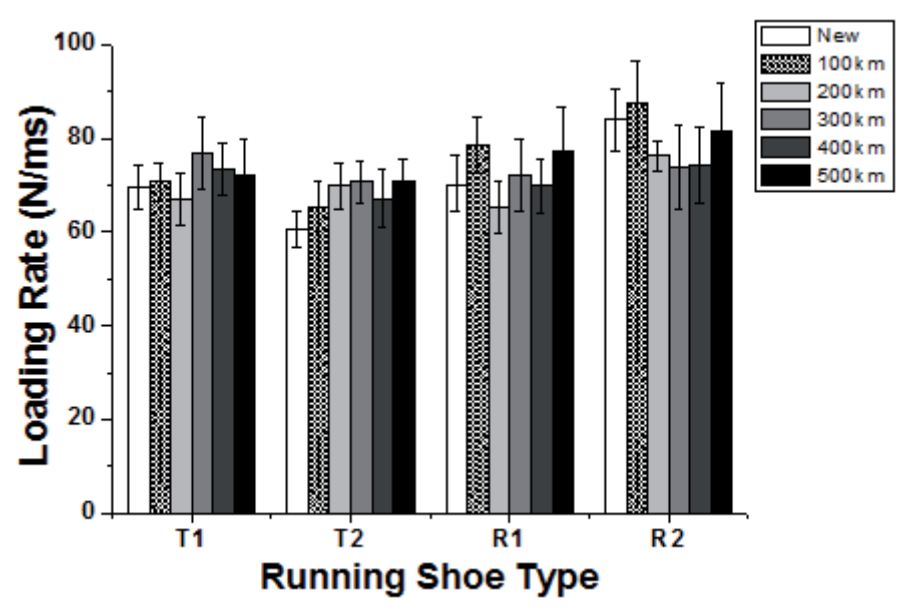

FIGURE 1 - Loading Rate values on shoes T1, T2, R1 and R2 on the different distances of use from New until $500 \mathrm{~km}$.

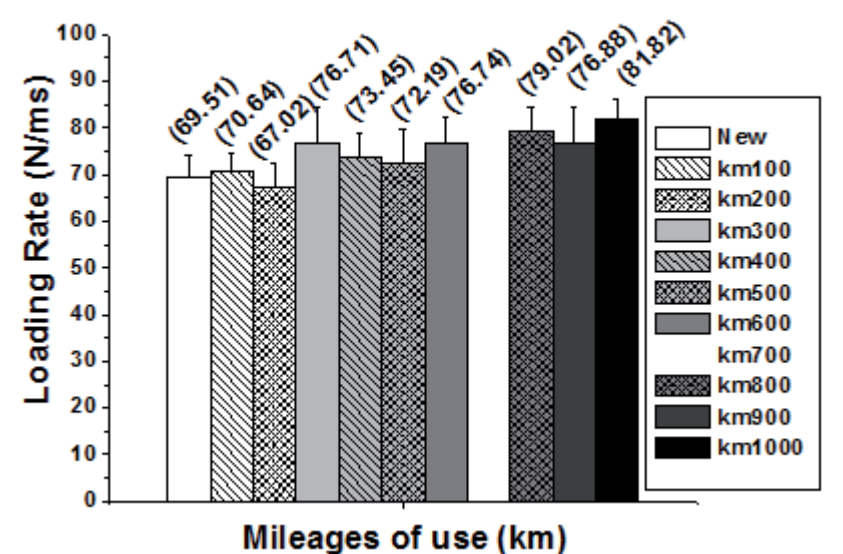

FIGURE 2 - Influence of running distance $(1000 \mathrm{~km})$ on Loading Rate values on shoe T1. 

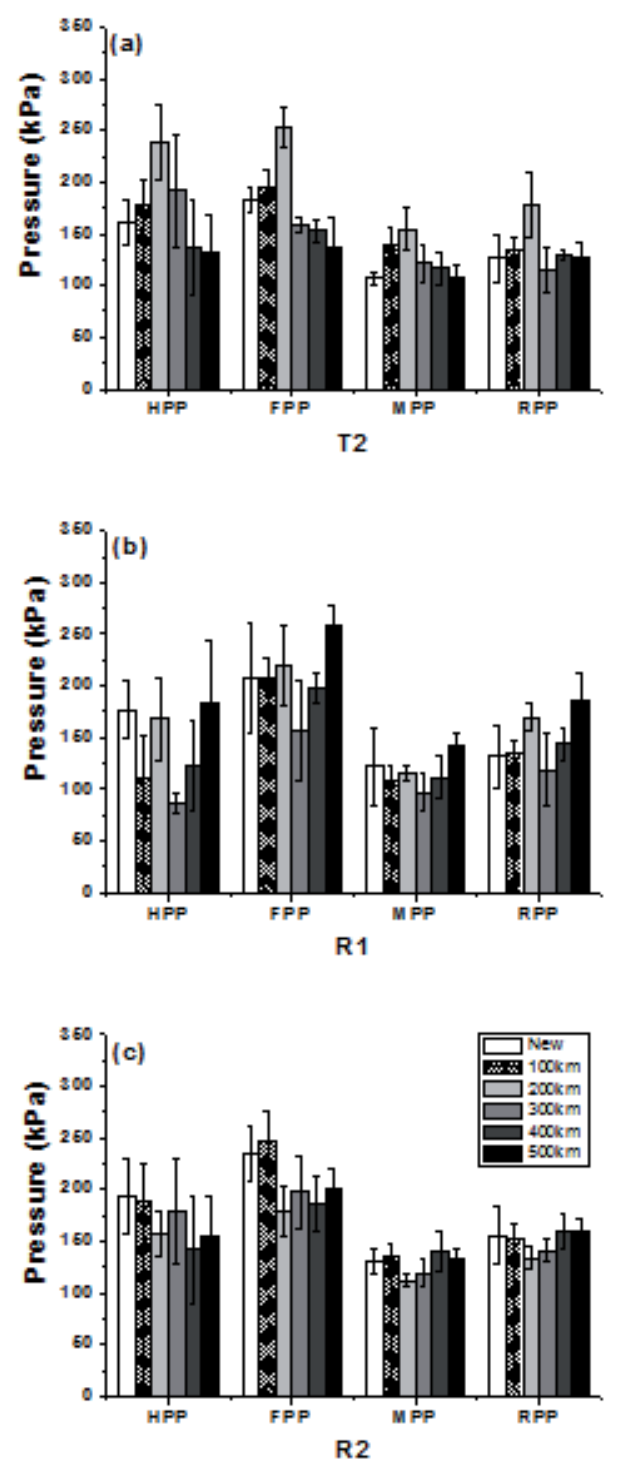

FIGURE 3 - Mean peak pressure on the Hállux (HPP), Forefoot (FPP), Midfoot (MPP) and Rearfoot (RPP), for the T2 (a), R1 (b) and R2(c) shoes along the different distances of use.

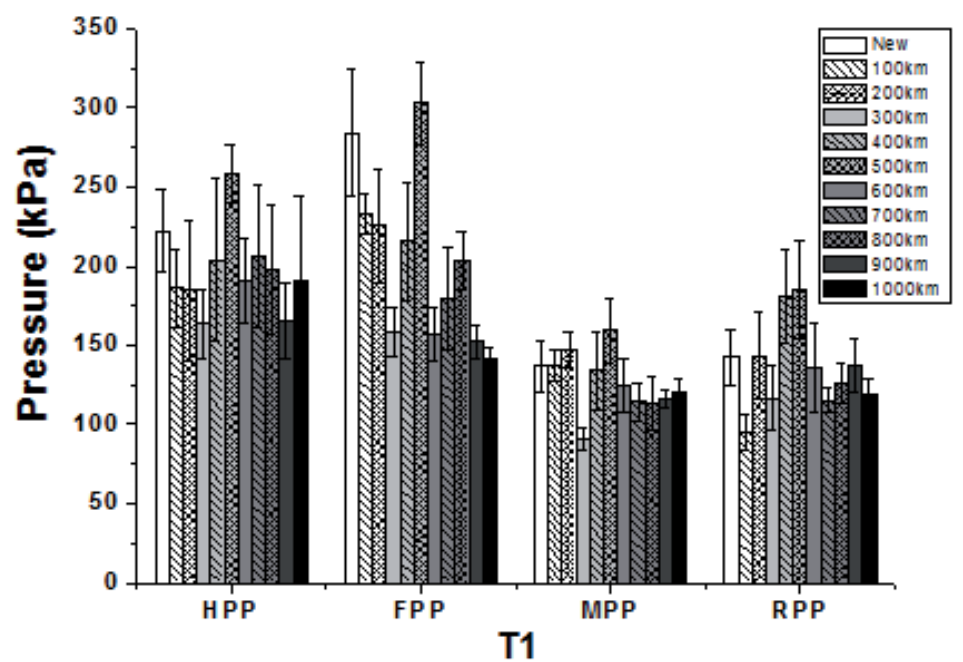

FIGURE 4 - Influence of running distance (100okm) on Peak Pressure values on T1 shoe. The Peak pressures on the Rearfoot (RPP), Midfoot (MPP), Forefoot (FPP) and Hállux (HPP) are shown. 


\section{Discussion}

The aim of this study was to investigate the kinetic responses of some running shoes submitted to high distances of use. The four running shoes were used until three of them reached $500 \mathrm{~km}(\mathrm{R} 1, \mathrm{R} 2$, and T2) and one of them reached $1000 \mathrm{~km}$ (T1).

While running, mechanical loads are applied to the structures of the locomotor system. These mechanical loads, especially those related to passive force, have been associated with many chronic injuries in running ${ }^{1,12-13}$. Therefore, it is suggested that these mechanical loads should be controlled, for example by the cushioning properties of the running shoes ${ }^{14-15}$. The variables to be controlled are especially those related to the passive phase, First Peak and Loading Rate (rate of increase of First Peak).

In this investigation, no clear trend of increase was observed in Loading Rate that would imply that mechanical load increased with usage in R1, R2 and T1. The variability in Loading Rate values between the conditions of use seemed different for each running shoe, suggesting that these shoes responded differently to usage. Only the T2 shoe showed a relatively consistent increase in Loading Rate from a new condition to $200 \mathrm{~km}$ and maintenance in its values until $500 \mathrm{~km}$. Despite the increase, the Loading Rate values were not higher at $500 \mathrm{~km}$ than the values of other shoes at the same distance, suggesting that despite the increase, the shoes did not present higher mechanical loads. The results of this study are in accordance with those observed in the literature ${ }^{7,16}$.

CoOK et al. ${ }^{2}$ observed that the effect of usage is different depending on running shoe construction. Although, the authors used mechanical tests to evaluate the deterioration of the shoes, aging of the running shoes was caused by runners. It is possible that the deterioration of the running shoe depends on factors such as the running style and body weight of the runner, running trail and surfaces selected for the training sessions, and variations on climatic conditions during the period in which the running shoe is used. All these factors affect the way the running shoes will be deteriorated and therefore could affect the kinetic responses during running. Assuming that the running shoes did suffer some deterioration, even though it was not measured, it could be speculated that the cumulative compaction of the running shoes generated different interactions with the locomotor system, but the kinetic responses do not seem to show increased mechanical loads with the deterioration of these shoes.
It is speculated that the variation in Loading Rate responses could be caused by the natural variability of human movement and by the interaction of the locomotor system to the deterioration of the running shoes caused by the cumulative use. The locomotor system is an important element in controlling the mechanical loads during running ${ }^{5,16}$ and it should be included in the analyses of the running shoe.

Hamill and BATES 5 observed no significant differences in mean impact forces and Loading Rate in running shoes submitted to $420 \mathrm{~km}$ of use. In their results, they noticed that five of the six subjects showed an increase in impact forces and in Loading Rate, but one subject showed a decrease in these parameters. According to the authors, this one subject could have presented a distinct adaptation to the running shoe in comparison to other subjects. Considering that the running shoe of this subject has suffered similar deterioration to the running shoes of the other subjects, it seems that the efficiency in controlling the mechanical loads in running is more dependent on the adaptation that one subject would show to the running shoe than on the preservation of shock absorption of the shoe. Consequently, the mechanical response in running depends on the interaction of subject and running shoe and not on the running shoe exclusively.

Therefore, it is possible that other subjects would present distinct results from those observed in this study. This means that the average result of a sample is dependent on the adaptive response that each individual has to the running shoe submitted to use. A sample may present positive or negative responses on the attenuation of mechanical loads depending on individual adaptive responses. What makes the adaptation of an individual efficient in controlling mechanical loads is not yet sufficiently understood, but this study indicates that a deterioration of $500 \mathrm{~km}$ of use, not necessarily implies that mechanical load attenuation has become worse because the key element is not the shoe but the adaptive response of the runner to the condition.

T1 presented a trend of gradual increase in Loading Rate values (FIGURE 2). Although the mechanical loads have increased progressively, the Loading Rate values at $1000 \mathrm{~km}$ of use were still similar to the values found in other shoes, for example, shoes R1 and R2 at $500 \mathrm{~km}$ of use. It is difficult to know when a running shoe becomes unsuitable for use, because a specific distance for 
that has not yet been determined, but $1000 \mathrm{~km}$ seems to be what most runners would avoid in a running shoe. These results may suggest that if one runner chooses to abandon a running shoe, it may not be because the mechanical loads became unwontedly high.

The Plantar Pressure distribution indicates force concentrations and abnormal application of mechanical loads on certain structures of the foot. This abnormal application of force associated with high volumes of mechanical load increases the probability of injury occurrence ${ }^{17}$. To prevent these injuries, an appropriate plantar pressure distribution is needed. One element that may interfere with the pressure distribution is the running shoe, so the plantar pressure distribution should be analyzed to better understand the mechanical interaction between the shoe and foot ${ }^{18}$.

In running shoes, the pressure distribution depends on the characteristics of the shoe, such as thickness and density of the midsole ${ }^{18}$, the format and material used in the insole ${ }^{19}$, anthropometrical characteristics of the athlete's foot ${ }^{20}$, and the runner's movement pattern.

In this investigation, plantar peak pressure values showed a high variation in all running shoes and in all regions of the foot, through the different distances of use. The highest peak pressure values were observed in the forefoot and the Hallux in most running shoes and distances (FIGURE 3). The higher peak pressures values may have occurred because of the relatively high running speed during the data collection requiring higher forces in the forefoot to generate greater propulsion. Although the running speed was relatively high, the subject did not change his running technique from rearfoot to midfoot running.

T2 and R2 presented similar or lower peak pressure values. R1 presented a high variability between conditions of use, but with no clear trend of increase or decrease. T1 presented similar or higher peak pressure values at $500 \mathrm{~km}$ than in a new condition. There was a great variation along the different distances of use. It is not possible to determine the cause of this variation, it is speculated that it could be caused by the nature of the measurement, or the selected parameter, or by changes in running technique, other than initial contact technique. The peak pressure values are the highest pressure measurements at a foot region during the stance phase in running. Although it is a discrete measure, it reflects the increase of pressure values, but this measurement cannot illustrate the distributions of forces in the entire plantar area. This characteristic associated to possible slight differences in running technique may account for the variations observed in pressure results. It is not possible to establish the interference of these factors on the results; therefore it is only a speculation.

The effect of usage on plantar pressure distribution is controversial ${ }^{3-4}$. In VERDEJO and MILLS ${ }^{4}$, the plantar peak pressure values tended to increase continuously over the distances of use. It should be pointed out that the authors presented the peak pressure values only on the heel region and for only one subject. The authors discussed that the increase in the magnitude of heel peak pressure values was over $100 \%$. On the other hand, DixON ${ }^{3}$ observed no significant difference between the new and the old shoe. This could mean that plantar pressure distribution is dependent on the shoe construction, the characteristics of the runner and the way the running shoe is imposed to compaction. This interaction could result in higher pressure values, which could be inadequate, or in lower peak pressure that could be beneficial to the runner, since high pressure values could lead to injuries over time ${ }^{17}$.

It would be expected that the racing shoes in general show higher peak plantar pressure with increasing use than the training shoes ${ }^{3}$. The results showed higher peak pressure values in R1, but no increase in peak plantar pressure was observed in R2 with increasing mileages of use (FIGURE 3).

The highest peak pressure values were observed in T1 and R1, therefore not necessarily a training shoe will present better results and a racing shoe will present worse results. This could raise the question that the difference in construction of these two shoes could not be sufficient to determine the kinetic responses of these two shoe types. This can indicate that the purpose attributed to the shoe by its manufacturer, racing and training, may not be sufficient to consistently indicate the kinetic response of the shoe. It should also be considered that these results are very much dependent on the interaction of the running shoe with the runner, as discussed before.

The peak pressure values in $\mathrm{T} 1$ showed a high variability until $500 \mathrm{~km}$ was reached (FIGURE 4), but after $500 \mathrm{~km}$ until $1000 \mathrm{~km}$, variability decreased and peak pressure became lower than those seen in a new shoe condition. The variation observed in the first $500 \mathrm{~km}$ shows no clear trend in values, but after $500 \mathrm{~km}$, all peak pressure values, in all regions of the foot were lower than in a new condition. It is not possible to determine the cause 
of the reduction in peak pressure values after 500 $\mathrm{km}$. More running shoes should be used in high distances to better understand the interaction between the runner and the shoe.

The Loading Rate and pressure measurements do not indicate that after $500 \mathrm{~km}$, and even after 1000 $\mathrm{km}$, the running shoe necessarily will present higher mechanical loads or worse attenuation of forces. Some discordance is still observed in the literature with respect to the shoe's durability, but apparently the discordance is caused by the variation observed in individual adaptation to the running shoe when imposed to use. Even though only one subject was analyzed, this study offers an indication that the running shoe may be more resistant to usage than it was originally imagined. Maybe the effect of usage, over the running shoes, affects other aspects of running that were not measured in this study. Therefore, studies using higher distances should be conducted to understand when the running shoe and runner interaction become inefficient and the running shoe should be considered worn out.

In conclusion, the running shoes analyzed in this study did not present higher mechanical loads and worse plantar pressure distribution with increasing use. The racing shoes did not show a lower durability than the training shoes. However, these observations are limited to the shoes tested and in the distances imposed in this study. The running shoes did present different responses to the increasing distances, therefore, different responses may arise in shoes with different constructions. It is important to remember that the biomechanical responses are dependent on the adaptation to the condition, therefore other subjects could present completely distinct results from those observed in this study. It would be interesting and necessary in future investigations to analyze this and other running shoes with high distances of use and with more subjects to confirm the responses observed in this study.

\section{Resumo}

Respostas dinâmicas em calçados de corrida submetidos ao uso prolongado: um relato de caso.

0 objetivo foi analisar as respostas dinâmicas em calçados de corrida submetidos ao uso prolongado. Quatro calçados (R1, R2, T1 e T2) foram submetidos ao uso prolongado na corrida. R1, R2 e T2 foram usados por $500 \mathrm{~km}$ e T1 por $1000 \mathrm{~km}$. A cada $100 \mathrm{~km}$, foram coletadas a Força de Reação do Solo e a pressão plantar. Em T2, houve uma ligeira tendência de aumento na taxa de crescimento do primeiro pico de força vertical (TC1) com o aumento da quilometragem de uso. R1, R2 e T1 não mostraram tendência de aumento nos valores de TC1. 0 calçado T1 apresentou uma ligeira tendência de aumento nos valores de TC1 nas quilometragens de uso até $1.000 \mathrm{~km}$. Todos os calçados de corrida mostraram alta variabilidade nos valores de pico de pressão, mas sem tendência clara de aumento. Pelo contrário, T1, T2 e R2 mostraram uma tendência de diminuição dos valores da pressão de pico com quilometragens crescentes de uso. Portanto, não há nenhuma evidência consistente ou tendência de aumento de nos valores de TC1 ou de pico de pressão que pudesse sugerir piora na atenuação de carga externa.

Palavras-chave: Biomecânica; Calçado; Uso cumulativo.

\section{References}

1. Frederick EC. Biomechanical consequences of sport shoes design. Exerc Sport Sci Rev. 1986;14:375-400.

2. Cook SD, Kester MA, Brunet ME. Shock absorption characteristics of running shoes. Am J Sports Med. 1985;13:248-53.

3. Dixon SJ. Use of pressure insoles to compare in-shoes loading for modern running shoes. Ergonomics. 2008;51:1503-14.

4. Verdejo R, Mills NJ. Heel-shoe interactions and durability of EVA foam running-shoe midsoles. J Biomech. 2004;37:1379-86.

5. Hamill J, Bates BT. A kinetic evaluation of the effects of in vivo loading on running shoes. J Orthop Sports Phys Ther. 1988;10:47-53.

6. Serrão JC, Sá MR, Amadio AC. Influência dos calçados de futsal no desempenho. Braz J Biomech. 2000;1:39-47. 
7. Kong PW, Candelaria NG, Smith DR. Running in new and worn shoes: a comparison of three types of cushioning footwear. Br J Sports Med. 2009;43:745-9.

8. Bianco R, Azevedo APS, Fraga CHW, et al. The influence of running shoes cumulative usage on the ground reaction forces and plantar pressure responses. Rev Bras Educ Fís Esporte. 2011;25:583-91.

9. Cavanagh PR, Rodgers MM. The arch index: a useful measure from footprints. J Biomechanics. 1987;20:547-51.

10. Wolery M, Harris SR. Interpreting results of single-subject research designs. Phys Ther. 1982;62:445-52.

11. White OR, Haring NG. Exceptional teaching. Columbus:Charles E. Merrill; 1980. p.331-6.

12. Nigg BM, Segesser B. Biomechanical and orthopedic concepts in sport shoe construction. Med Sci Sports Exerc. 1992;24:595-602.

13. Davis IM, Ferber R, Dieckers TA, Butler RJ, Hamill J. Variables associated with the incidence of lower extremity stress fractures. 4th World Congress of Biomechanics; 2002; Calgary, CA. Calgary: University of Calgary; 2002.

14. Hreljac A. Impact and overuse injuries in runners. Med Sci Sports Exerc. 2004;36:845-9.

15. Richards CE, Magin PJ, Callister R. Is your prescription of distance running shoes evidence based? Br J Sports Med. 2009;43:159-62.

16. Serrão JC, Sá MR, Amadio AC. Effects of running shoe wear in dynamical aspects of locomotion. I Brazilian Sympozium of Shoe Biomechanics. Gramado: UDESC/CEFID, p.23-7, 2001.

17. Peterson L, Renström P. Sports ilnjuries: their prevention and treatment. Champaign: Human Kinetics; 2001.

18. Hennig EM, Milani TL. In-shoe pressure distribution for running in various types of footwear. J Appl Biomech. 1995;11:299-310.

19. Nigg BM, Herzog W, Read LJ. Effect of viscoelastic shoe insoles on vertical impact forces in hell-toe running. Amer J Sports Med. 1988;16:70-6.

20. Sneyers CJL, Lysens R, Feys H, Andries R. Influence of misalignment of the feet on the plantar pressure pattern in running. Foot Ankle Int. 1995;16:624-32.

\section{Acknowledgement}

The authors would like to thank the manufacturers of the running shoes for their donation. No other financial support was received for this project.

\begin{tabular}{r|l} 
ENDEREÇo & \\
Roberto Bianco & \\
Escola de Educação Física e Esporte - USP & Recebido para publicação: 12/09/2012 \\
Av. Prof. Mello Moraes, 65 & 1a. Revisão: 03/04/2013 \\
05508-030 - São Paulo - SP - BRASIL & 2a. Revisão: 11/05/2013 \\
e-mail: bianco.rob19@gmail.com & Aceito: 29/05/2013 \\
&
\end{tabular}

